\title{
DISCLAIMER
}

This report was prepared as an account of work sponsored by an agency of the United States Government. Neither the United States Government nor any agency thereof, nor any of their employees, makes any warranty, express or implied, or assumes any legal liability or responsibility for the accuracy, completeness, or usefulness of any information, apparatus, product, or process disclosed, or represents that its use would not infringe privately owned rights. Reference herein to any specific commercial product, process, or service by trade name, trademark, manufacturer, or otherwise does not necessarily constitute or imply its endorsement, recommendation, or favoring by the United States Government or any agency thereof. The views and opinions of authors expressed herein do not necessarily state or reflect those of the United States Government or any agency thereof.

\section{Diagnostic Studies of Climate Variability}

Annual Report to the U.S. Department of Energy for the period December 1, 1991 - November 30, 1992

\author{
Raymond S. Bradley \\ (University of Massachusetts, Amherst) \\ and \\ H.F. Diaz \\ (NOAA/ERL/CMDL/CRD, Boulder, Colorado)
}

\author{
Prepared for
}

THE U.S. DEPARTMENT OF ENERGY

Agreement No. DE-FG02-89ER69017

with the University of Massachusetts, Amherst. 


\section{Diagnostic Studies of Climate Variability}

Research Objectives for 1991-1992

Our objectives in 1991-92, the first year of the project, were as follows:

a) To initiate studies of lorig-term climatic variability, using long instrumental data sets, and proxy records. These are intended to extend our understanding of climatic changes back into the period before there were global-scale anthropogenic effects on atmospheric composition.

b) To examine regional changes of temperature and precipitation over the past century in relation to changes at the hemispheric and global scale

c) To produce a map-based archive of monthly and seasonal temperature, precipitation and pressure data for display on PCs.

Significant progress has been made in all of these areas. In the following section we summarise results of the work accomplished. Part A summarises the work accomplished primarily at the University of Massachusetts. Part B summarises work primarily conducted at NOAA/ERL. However, both investigators have closely :ollaborated on all aspects of the work. A list of papers published, in press, or in preparation then follows.

Appendix 1 is a description of the proposed research in 1992-93, and a proposed budget ${ }^{1}$.

\section{Part A}

\section{Studies of long-term climate variability}

Although there are a small number of instrumentally recordet temperature records extending back in time before the early to mid-nineteenth century, most of these are confined to western Europe. To construct a record which reflects the longterm fluctuations of temperature on a hemispheric or global scale requires a more extensive network, or a limited set of data which can be considered representative of larger scale conditions (cf. Bradley. et al., 1987). This requires a better understanding of

\footnotetext{
${ }^{1}$ All of these items are discussed more extensively in the longer ( 3 year) proposal entitled; "Diagnostic Studies of Climate Variability" (UMASS proposal 91A1185) submitted May 16, 1991.
} 

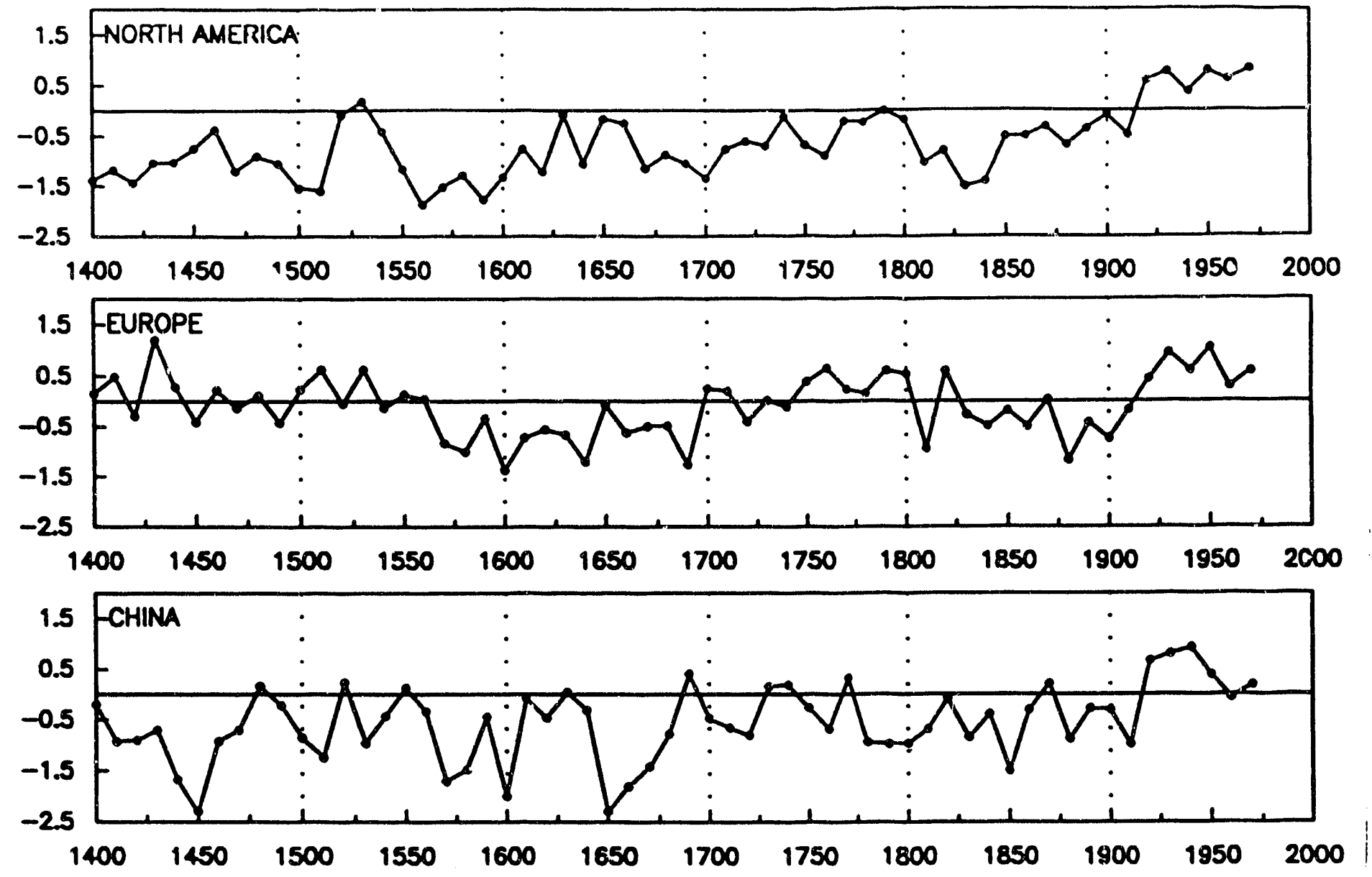

Figure 1: Average normalized anomalies of summer temperature, based on a set of proxy records for the regions indicated (from Bradley and Jones, in preparation) 
the relationship between regional and global-scale climatic fluctuations (see section 2, below). Inevitably, either strategy requires the incorporation of paleoclimate (proxy) data which contains a strong climatic signal (Bradley and Jones, 1992). We have identified a number of records from around the world which can be used to extend the record of regional temperature back several hundred years (Bradley and Jones, in preparation). To what extent these can be relied upon to provide a record of hemispheric or global temperature is currently being investigated. At present we have some confidence in the reconstructions of regional-scale summer temperature (Figure 1) and we are investigating reconstructing records for the other seasons.

2. Regional scale climatic fluctuations.

To investigate the relationship between regional and larger-scale climatic fluctuations, we have divided the DOE data sets of temperature and precipitation into a number of sub-regions. We have reported previously on studies of regional precipitation trends, based on an objective scheme for identifying regions with a common signal. Fluctuations of temperature within those same regions have also been investigated and are the subject of a paper in preparation (Diaz et al, 1992). We have also divided the world into less objective but perhaps more meaningful geopolitical regions, to investigate how temperature changes in these regions relate to the larger scale. This includes both land and oceanic regions. Figures 2 and 3 illustrate some of these regional records, expressed as departures from the 1951-70 period. Dashed and solid vertical lines indicate the dates on which data coverage increases to $>25 \%$ or $>50 \%$, respectively, of the area of the region in question. Thus, for example, the North Atlantic has data for $50 \%$ or more of the region from the early 1880 s, whereas in the South Atlantic, such coverage is only available from the early 1950s. We have also examined how the temperature changes in these areas, based on surface-based instrumental records, relate to satellite-derived (MSU) lower tropospheric temperature estimates since 1979 (Table 1). These comparisons show that in many regions the MSU data are highly correlated with the surface temperature records, but elsewhere the correspondence is very poor (for example, compare the MSU versus North Atlantic and South Atlantic correlation coefficients in Table 1). Indeed, the correlation of MSU and surface temperature data is closely related to the geographic coverage of surface temperature data in each region. We believe that this analysis points to significant problems in using "long-term" data from some areas where data coverage is currently poor, and cautions against placing much reliance on temperature trends in regions where records are severely eroded back in time (cf. Bradley, 1991). This then raises 


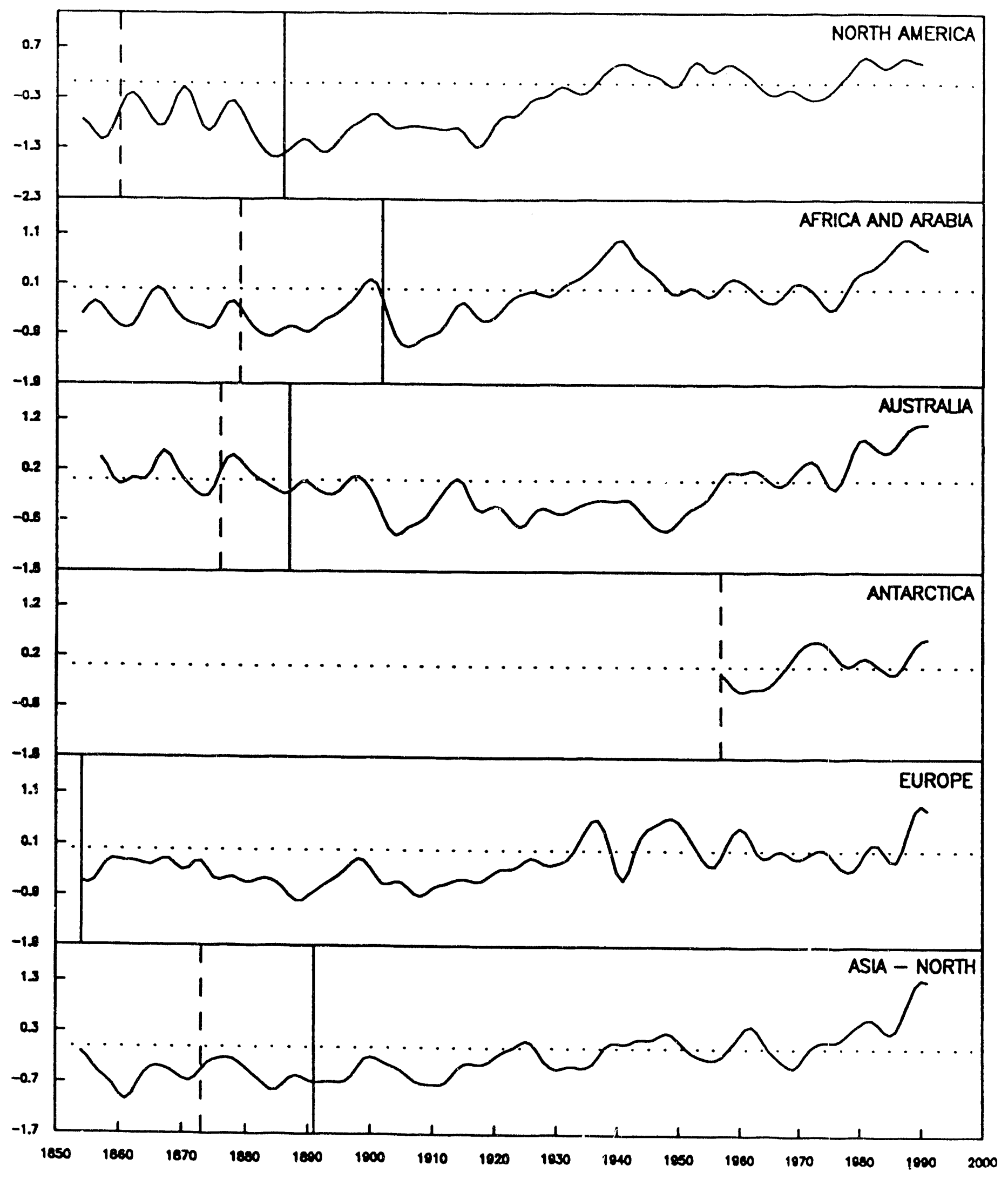

Figure 2: Normalized temperature anomalies for selected regions, expressed as anomalies from 1950-1979, smoothed by a 10 year Gaussian filter. Vertical solid and dashed lines represents date at which data coverage drops to $50 \%$ and $25 \%$, respectively, of the area of the region in question. 


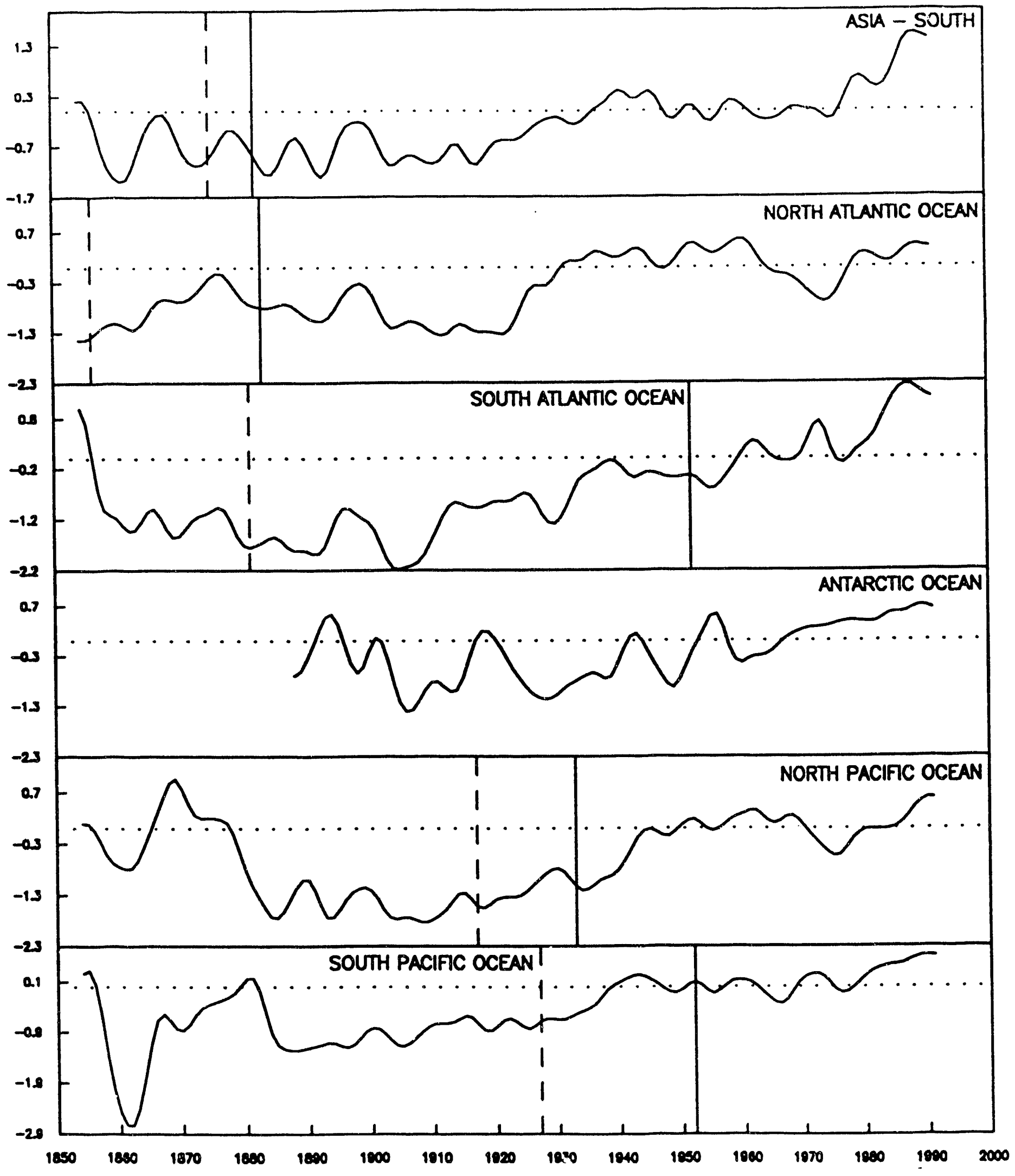

Figure 3: See caption to Figure 2. 
Table 1: Correlations between surface and MSU series (1979-1991)

\begin{tabular}{|c|c|c|c|c|c|}
\hline & winter & Spring & Summer & Fall & Annual \\
\hline North America & .782 & .692 & .863 & .916 & .896 \\
\hline South America & .581 & .918 & .705 & .736 & .636 \\
\hline Greenland & .775 & .561 & .395 & .626 & .619 \\
\hline Africa & .819 & .755 & .583 & .807 & .722 \\
\hline Australia & .328 & .583 & .663 & .960 & .853 \\
\hline Antarctica & .153 & .821 & .883 &.$\$ 84$ & .836 \\
\hline Europe & .916 & .890 & .642 & .733 & .911 \\
\hline Asia - North & .714 & .809 & .800 & .902 & .827 \\
\hline Asia - South & .736 & .637 & .631 & .854 & .772 \\
\hline North Atlantic Ocean & .365 & .830 & .624 & .855 & .846 \\
\hline South Atlantic Ocean & .095 & .253 & .105 & .118 & .082 \\
\hline Indian Ocean & .811 & .757 & .906 & .825 & .881 \\
\hline Antarctic Ocean & .297 & .667 & .458 & -.070 & .107 \\
\hline Arctic Ocean & -.146 & -.398 & .405 & .588 & -.044 \\
\hline North Pacific Ocean & .270 & .100 & .318 & .377 & .268 \\
\hline South Pacific Ocean & .447 & .174 & .556 & .275 & .394 \\
\hline Northern Hemisphere & .697 & .669 & .826 & .873 & .824 \\
\hline Northern Hemisphere Land & .818 & .752 & .822 & .947 & .899 \\
\hline Southern Hemisphere & .388 & .703 & .600 & .437 & .550 \\
\hline Southern Hemisphere Land & .465 & .833 & .621 & .563 & .633 \\
\hline Globe & .822 & .679 & .746 & .778 & .754 \\
\hline Globe Land & .870 & .779 & .793 & .897 & .836 \\
\hline Globe Sea & .655 & .544 & .675 & .589 & .645 \\
\hline
\end{tabular}


questions about the veracity of so-called "global" temperature series for the last $100+$ years.

3. Map-based archives of monthly and seasonal climate

Previous work has involved production of long-term data sets of temperature and precipitation which are now widely used by the climatological community for research purposes. We have converted these data sets into a map-based archive in which the data have been color-coded and interpolated onto a world map, simultaneously displayed in the form of both Mercatur and polar projections. A menudriven system allows the user to select temperature, precipitation, sea-level or $500 \mathrm{mb}$ pressure fields, and to step through the archive on a monthly,seasonal or annual basis. The user can also "flip" from one field to another for a given point in time. The maps were produced on a Silicon Graphics workstation, using an extensive color palette, and then converted to GIF format which permits the data to be displayed on a variety of PCs with excellent color reproduction. We are currently discussing with the Carbon Dioxide Information Center (Oak Ridge) the possibility of distributing these data in CD format. Although the data sets themselves are currently available in digital form from Oak Ridge or from NCAR, making these map-based images available permits rapid display of individual months without the need for graphics software and the considerable effort often needed to display spatial data.

\section{References}

Bradley, R.S., 1991: Instrumental records of past global change: lessons for the analysis of non-instrumental data. In: Global Changes of the Past (ed. R.S. Bradley). UCAR/OIES, Boulder Colorado, p.103-115.

Bradley, R.S. and P.D. Jones, 1992: Climate Since A.D. 1500: Introduction. In: Climate Since A.D. 1500 (eds. R.S. Bradley and P.D. Jones). Routledge, London, 1-16.

Bradley, R.S. and P.D. Jones, 1992: The "Little Ice Age" (in preparation)

Bradley, R.S., H.F. Diaz, P.D. Jones and P.M. Kelly, 1987: Secular fluctuations of temperature over northern hemisphere land areas and mainland China since the mid-nineteenth century. In: The Climate of China and Global Climate (Eds., D.Ye, C.Fu, J. Chao and M. Yoshino. China Ocean Press, Beijing, 76-87.

Diaz, H.F. and J.K. Eischeid and R.S. Bradley, 1992: Secular changes in precipitation and temperature over global land areas. Part I: Regionalization and assessment of trends (in preparation). 


\section{Part B}

Work performed at NOAA/CRD

For year 1 of the project, we had set out the following activities to be carried out under the subcontract to NOAA/CRD. These were:

1. To begin to assembling data on atmospheric circulation changes, testing statistical procedures for regionalization and re-gridding of data fields.

2. Explore different techniques and ideas regarding climate regionalization and evaluate differences.

3. Collaborate with R. S. Bradley on work aimed at finding suitable regions where the low frequency temperature response is similar to those of hemispheric scale indices.

Below we described progress made toward these goals, and outline our work plan for year 2 of the project.

Circulation Indices, Climate Regionalization and Gridding.

We have acquired software to determine the position and central pressures of extratropical low- and high-pressure centers for future studies of largescale circulation changes in the Northern Hemisphere during the 1920s and $30 \mathrm{~s}$ in comparison with the 1980s. In preparation for a regridding of the global land grid temperature data set, we are exploring a number of analysis techniques based upon objective interpolation and krigging concepts (Brown and Eischeid, 1992).

Considerable work has been done on climate classification methods. We have applied two traditional statistical techniques in a new way to try to objectively define "natural" climatic regions. These techniques, a combination of R-mode principal components analysis (see, e.g., Stidd, 1967; Skaggs, 1975) and cluster analysis (Hartigan, 1975) have been applied to the regionalization of sea surface temperature (SST) over the world 
oceans (Diaz and Brown, 1992; 1993), and to define precipitation regions over land areas (Diaz, 1991).

Studies of the impact of climatic fluctuation on mid-sized river basins in the western United States is being done as part of a Master Thesis at the University of Colorado, Boulder. The study involves the use of a hydrologic model to study streamflow variations on the Platte River.

Work has also been done on data visualization algorithms for use on computer work stations. This includes the implementation of a Geographic Information System (GIS) package (GRASS) on a SUN computer workstation and the linking of various data bases, such as the NOAA/NGDC high-resolution topographic elevation data set, world vegetation and soils regions, and graphics display modules such as NCAR Graphics and others.

\section{Collaborative Work}

Regarding item 3, above, Bradley and Diaz have collaborated on studies aimed at documenting changes in arctic surface-based inversion layers (Bradley et al. 1992a,b). Work is also being done at NOAA to evaluate climatic changes in the western United States with an emphasis on studying the relationship of those changes to surface elevation, and seasonal precipitation amounts. Preliminary results of this work (Brown and Diaz, 1993) will be presented at the AMS Globai Change Symposium, in Anaheim, California in January 1993.

Diaz and Bradley are continuing their collaboration on studies of regional climatic change. They have contributed a manuscript (Diaz and Bradley, 1992) and will present a talk at a NAS/CRC sponsored wor kshop on the subject of global climate change in September 1992. One topic addressed in this study is concerns questions regarding changes in climatic variance associated with changes in climatic means.

\section{References Cited}

Hartigan, J. A., 1975. Clustering Algorithms. J. Wiley \& Sons, New York, $351 \mathrm{pp}$.

Skaggs, R. H., 1975. Drought in the United States, 1931-40. Annals of the Assoc. of Amer. Geogr., 65, 391-402.

Stidd, C. K., 1967. The use of eigenvectors for climatic estimates. J. Appl. Meteor., 6, 255-264. 


\section{PUBLICATIONS ARISING FROM RECENT DEPARTMENT OF ENERGY SUPPORT (1991-92)}

Bradley, R.S., 1992: Riscaldamente Globale? No Grazie. L'Impresa Ambiente, 3/92, 51-599in Italian).

Bradley, R.S., 1992: Reconstructions of climate from A.D. 1000 to the present. In: Global Climate Change, (ed. S. Tibaldi) DEMETRA Association, Bologna, Italy (in press)

Bradley, R.S. and Jones, P.D., 1992: Climate Since A.D. 1500: Introduction. In: Climate Since A.D. 1500 (eds. R.S. Bradley and P.D. Jones). Routledge, London, p.1-16.

Bradley, R.S. and Jones, P.D., 1992: Records of explosive volcanic eruptions over the last 500 years. In: Climate Since A.D. 1500 (eds. R.S. Bradley and P.D. Jones). Routledge, London, p.606-622.

Bradley, R.S. and Jones, P.D., 1992: When was the Little Ice Age? In: Proceedings of the International Conference on the Little Ice Age Climate (Ed. T. Mikami). Department of Geography, Tokyo Metropolitan University, Tokyo, 1-4.

Bradley, R.S., Keimig, F.T., and Diaz, H.F., 1992: Climatology of surface-based inversions in the North American Arctic. Journal of Geophysical Research (in press).

Brown, T. J. and J. K. Eischeid, 1991: An examination of spatial statistical techniques for interpolation of gridded climate data. Preprints, 12th AMS Conf. on Prob. and Stat. in the Atmos. Sci., Toronto, Canada.

Brown, J. T. and H. F. Diaz, 1993: Climate Variations in the Rocky Mountain West. Preprints, Fourth AMS Symposium on Global Change Studies, Anaheim, CA (January 1993).

Diaz, H. F., 1991: Changes in regional-scale precipitation for global land areas during the past century. Preprints, Fifth AMS Conf. on Climate Variations (Denver, Colo.), pp. 35-37.

Diaz, H. F. and R. S. Bradley, 1992: Documenting natural climatic variations: How different is the climate of the 20th century from that of previous centuries? NAS/BASC Workshop on Global Climate Change, Irvine , CA, September 1992.

Diaz, H. F. and T. J. Brown, 1992: Application of statistical techniques for the regionalization of marine surface temperature. Preprints, 12th AMS Conf. on Prob. and Stat. in the Atmos. Sci., Toronto, Canada.

Diaz, H. F. and T. J. Brown, 1993: An objective classification of clirnatic regions in the Pacific and Indian Oceans. Proceedings of the Ninth Annual Pacific Climate (PACLIM) Workshop (in press). 
Eischeid, J. K. and R. S. Pulwarty, 1991: Annual and seasonal patterns of rainfall variability in the central Amazon Basin. Preprints, Fifth AMS Conf. on Climate Variations (Denver, Colo.), pp.177-180.

Jones, P.D. and Bradley, R.S., 1992: Global-scale temperature changes during the period of instrumental records. In: Proceedings of the International Conference on the Little Ice Age Climate (Ed. T. Mikami). Department of Geography, Tokyo Metropolitan University, Tokyo, 253-259.

Jones, P.D. and Bradley, R.S., 1992: Climatic variations in the longest instrumental records. In: Climate Since A.D. 1500 (eds. R.S. Bradley and P.D. Jones). Routledge, London, p.246-267.

Jones, P.D. and Bradley, R.S., 1992: Climatic variations over the last 500 years. In: Clinate Since A.D. 1500 (eds. R.S. Bradley and P.D. Jones). Routledge, London, p.649-666.

\section{Papers in preparation or under review.}

Bradley, R.S. and Jones, P.D., 1992: The "Little Ice Age" (in preparation)

Bradley, R.S., F.T. Keimig, and H.F. Diaz, 1992: Recent changes in the Arctic atmospheric boundary layer in winter (in review).

Diaz, H.F. and R.S. Bradley, 1992: Long-term variations in temperature at high elevation sites in the Northern Hemisphere (in preparation).

Diaz, H.F. and J.K. Eischeid and R.S. Bradley, 1992: Secular char.ges in precipitation over global land areas. Part I: Regionalization and assessment of trends (in preparation).

Diaz, H.F., J.K. Eischeid, 1992: An analysis of the effect of varying spatial and temporal coverage on estimates of large-scale precipitation (in preparation). 


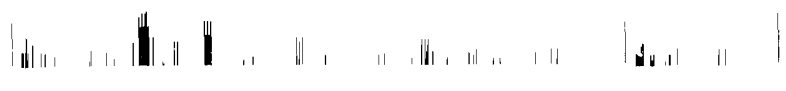
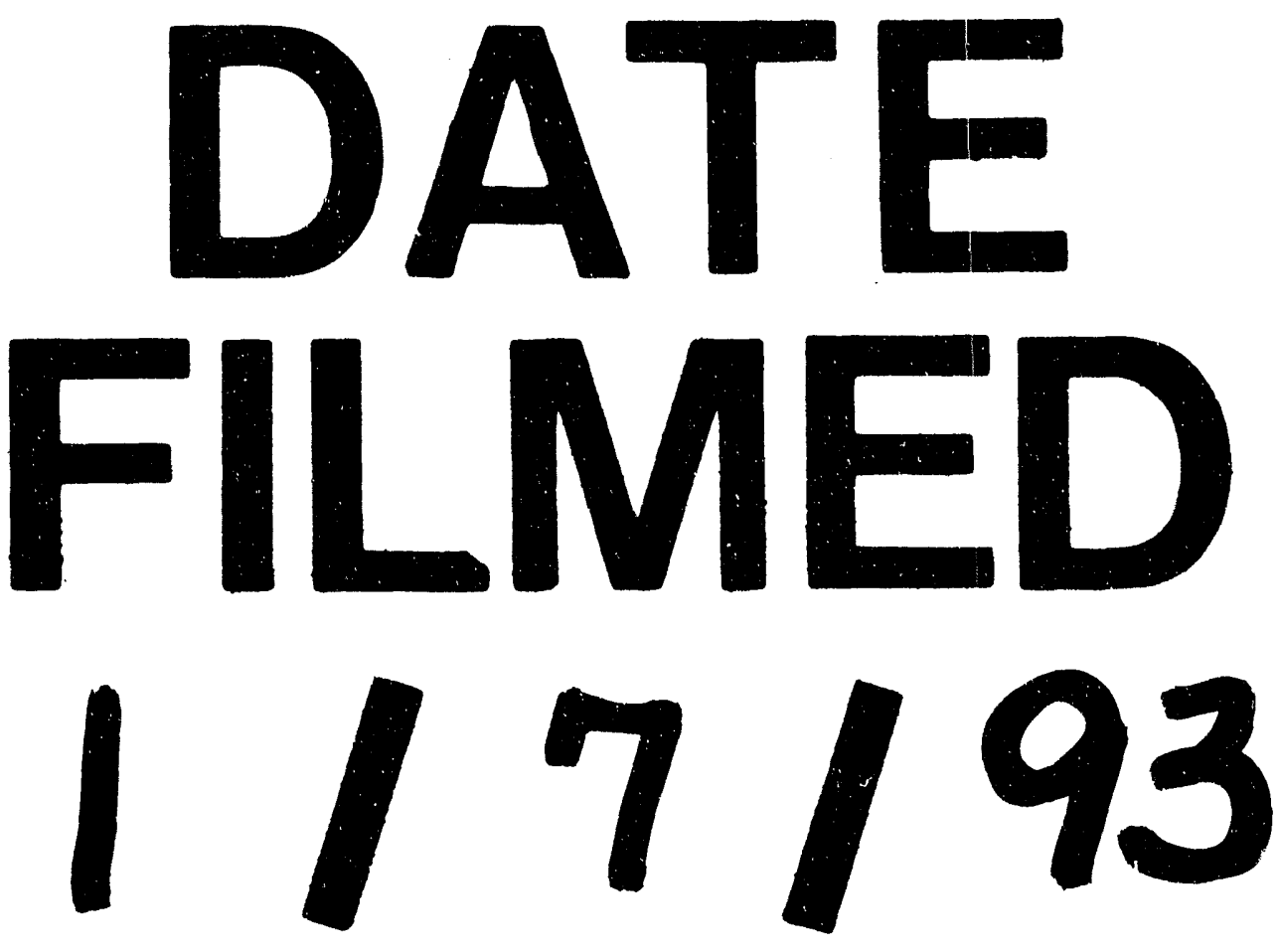
. 